\title{
ESTRUTURA PRODUTIVA E INDÚSTRIA ALIMENTAR NO PARANÁ, DE 1980 A 1995 $^{1}$
}

\author{
Rossana Lott Rodrigues ${ }^{2}$ \\ Antonio Carlos Moretto ${ }^{3}$ \\ José Joaquim Martins Guilhoto ${ }^{4}$
}

Resumo - Este artigo objetivou avaliar a evolução da estrutura produtiva e identificar os setores-chave da economia do Paraná, nos anos de 1980, 1985, 1990 e 1995, com destaque para a indústria alimentar, usando matrizes insumo-produto estimadas. Os resultados mostraram que os setores da indústria de transformação, ligados ao processamento alimentar, perderam importância relativa na economia paranaense, tanto no que se refere às ligações com os demais setores, quanto à geração de valor da produção e adicionado. Essa perda foi mais acentuada nos setores alimentares mais tradicionais, como Indústria do Café e Beneficiamento de Produtos Vegetais, do que nos mais modernos, a exemplo de Abate de Animais, Indústria de Laticínios, Fabricação de Açúcar e Fabricação de Óleos Vegetais. Outra tendência que pôde ser delineada foi a alteração na estrutura produtiva do Estado, que se tornou mais diversificada e complexa, com destaque para alguns setores do ramo serviços e outros emergentes da indústria de transformação, como metalurgia, mecânica e material de transporte. Além disso, a produção e a renda responderam menos aos impactos na demanda final nos setores alimentares, ao longo do período analisado.

Palavras-chave: insumo-produto, estrutura produtiva, setores-chave e indústria alimentar.

\section{Introdução}

No Paraná, duas tendências se manifestaram nos anos oitenta: na primeira metade da década, a economia estadual cresceu aos níveis da nacional e, na segunda, passou a ter desempenho superior ao do Brasil. Assim, no cômputo geral, a economia do Estado teve expansão média do PIB,

Os autores agradecem as sugestões dos pareceristas anônimos da REA.

2 Professora do Departamento de Economia da Universidade Estadual de Londrina. E-mail: rlott@uel.br

Professor do Departamento de Economia da Universidade Estadual de Londrina. E-mail: acmoretto@uel.br

4 Professor da FEA-USP e do Regional Economics Applications Laboratory (REAL), University of Illinois. E-mail: guilhoto@usp.br 
durante a década de 80 , de 5,6\% ao ano, contra 2,9\% da economia brasileira (Ipardes, 1991). A conformação do PIB paranaense, segundo as classes de atividade, está representada na Figura 1.

O início dos anos 90 foi marcado por profunda recessão nas economias brasileira e paranaense. No Paraná, os efeitos da conjuntura recessiva foram mais significativos, devido ao predomínio da agropecuária e da agroindústria na estrutura produtiva do Estado, resultando em retração de 6,6\% do PIB em 1990 (Volaco et al., 1991).

Apesar da profunda crise recessiva nos dois primeiros anos da década, com forte retração em muitos segmentos da atividade produtiva paranaense, o PIB estadual cresceu à taxa anual de $4,1 \%$ no período de 1990a 1993, enquanto o Brasil registrou crescimento de 1,4\% (Lourenço, 1994).

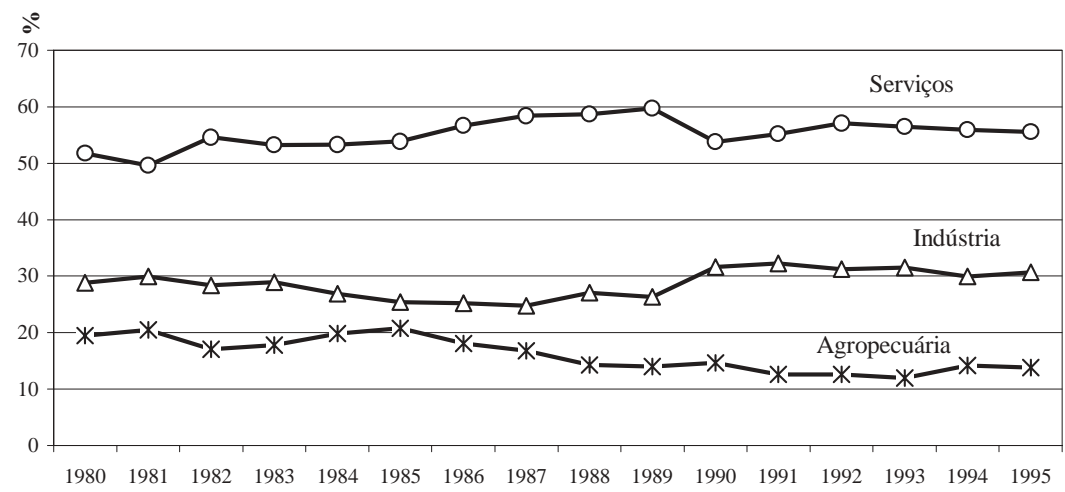

Figura 1 - Participação percentual das classes de atividade no PIB $_{\text {cf? }}$, Paraná, 1980-95.

Fonte: 1980 a 1989 (Volaco et al., 1991, p. 6), 1990 a 1994 (Ipardes, 1997a) e 1995 (Ipardes, 1998).

Em 1994, o PIB do Estado cresceu a uma taxa superior à média nacional, $6,6 \%$ e $5,7 \%$, respectivamente, fruto do excelente desempenho da 
indústria estadual, que apresentou crescimento de 9,2\% (Lourenço, 1995). Este comportamento sofreu alguma influência do setor público paranaense, que realizou investimentos em infra-estrutura.

A integração comercial do Brasil com os demais países do Mercosul contribuiu, significativamente, para o desempenho favorável no período 1993-94, quando as exportações paranaenses para o Mercosul elevaramse de 4,1\% para 14,9\%, em 1990 e 1993, respectivamente (Wosch, 1996).

O ano de 1995, do ponto de vista quantitativo, marcou forte retração no desempenho do parque manufatureiro estadual, que contabilizou um declínio de 5,6\% contra uma expansão de 1,7\% da indústria brasileira (Lourenço, 1996). A referida queda na produção industrial pode ser explicada pela conjunção da instabilidade agrícola e por suas repercussões multiplicadoras dinâmicas, para frente e para trás, na política de juros altos, na sobrevalorização do real e no esfriamento dos fluxos comerciais e de investimentos entre o Brasil e os países do Mercosul, especialmente com a Argentina.

Tendo este cenário como pano de fundo, esse artigo objetivou avaliar a evolução da estrutura produtiva e identificar os setores-chave na economia do Paraná, nos anos de 1980, 1985, 1990 e 1995, com destaque para o comportamento da indústria alimentar. Para isso, foram usadas as matrizes insumo-produto, estimadas para os anos citados, por Rodrigues (2000) e Moretto (2000).

Além desta introdução, o artigo está dividido em mais três. Na segunda, é descrita a metodologia, enquanto os resultados e as considerações finais são apresentados na terceira e na quarta, respectivamente. 


\section{Metodologia}

\subsection{Os indices de Rasmussen-Hirschman}

Os índices de ligações de Rasmussen-Hirschman têm sido muito aplicados e comentados, na literatura, por McGilvray (1977), Hewings (1982), Guilhoto et al. (1994), dentre outros.

Considerando a estrutura interna da economia baseada no modelo de insumo-produto e seguindo os dois últimos autores, é possível verificar os setores que têm os maiores índices de ligações para trás, que estimam o quanto um setor demanda dos outros, e os que apresentam os maiores índices de ligações para frente, que informam o quanto um setor é demandado pelos outros. Valores maiores que um, para ambos os índices, indicam setores acima da média e, portanto, setores-chave para o crescimento da economia.

Desse modo, com base na equação $L=(I-A)^{-1}$, tem-se que $I$ é a matriz identidade e $A$, matriz de coeficientes técnicos de insumos diretos; $l_{i j}$, elemento da matriz inversa, de Leontief, $L ; L^{*}$, média de todos os elementos de $L$ e $L_{\bullet j}$; e $L_{i \bullet}$, soma dos elementos de uma coluna e de uma linha típica de $L$, dada, respectivamente, por

$$
L_{\bullet j}=\sum_{i=1}^{n} l_{i j} \quad \text { e } \quad L_{i \bullet}=\sum_{j=1}^{n} l_{i j} \quad \mathrm{i}, \mathrm{j}=1,2, \ldots \mathrm{n} .
$$

Assim,

Índices de ligações para trás:

$$
U_{j}=\left[L_{\bullet j} / n\right] / L^{*} .
$$


Índices de ligações para frente:

$U_{i}=\left[L_{i \bullet} / n\right] / L^{*}$

\subsection{Abordagem GHS: os índices puros de ligação}

Os índices de ligações de Rasmussen-Hirschman, embora largamente aplicados, são criticados por não levar em consideração os diferentes níveis de produção em cada setor da economia. Com o intuito de corrigir essa deficiência, foi proposto, inicialmente, o enfoque Cella-Clements (Cella, 1984; e Clements, 1990), posteriormente, a visão do índice puro de ligações (Guilhoto et al., 1994) e, mais recentemente, a abordagem do novo índice puro de ligações, também denominado GHS (Guilhoto et al., 1996).

Neste estudo utilizou-se essa última abordagem, uma vez que ela considera a importância de dado setor para o resto da economia e sua interação com outros setores, em termos do valor da produção, além de corrigir um erro de decomposição, contido nos trabalhos de Cella (1984) e Clements (1990), e de aprimorar a versão inicial do índice puro de ligações, apresentada em Guilhoto et al. (1994).

Partindo da consolidação da abordagem GHS apresentada em Guilhoto et al. (1996), a matriz de coeficientes de insumos diretos, $A$, que representa um sistema de insumo-produto para dado setor, $j$, e o resto da economia, $r$, é dada por

$$
A=\left(\begin{array}{cc}
A_{j j} & A_{j r} \\
A_{r j} & A_{r r}
\end{array}\right),
$$

em que $A_{j j}$ e $A_{r r}$ são matrizes quadradas dos insumos diretos do setor $j$ e do resto da economia (economia menos o setor $j$ ), respectivamente; e $A_{r j}$ e $A_{j r}$, matrizes retangulares que mostram os insumos diretos comprados pelo setor $j$ do resto da economia e vice-versa. 
De (2.4) chega-se a

$$
L=(I-A)^{-1}=\left(\begin{array}{ll}
L_{j j} & L_{j r} \\
L_{r j} & L_{r r}
\end{array}\right)=\left(\begin{array}{cc}
\Delta_{j j} & 0 \\
0 & \Delta_{r r}
\end{array}\right)\left(\begin{array}{cc}
\Delta_{j} & 0 \\
0 & \Delta_{r}
\end{array}\right)\left(\begin{array}{cc}
I & A_{j r} \Delta_{r} \\
A_{r j} \Delta_{j} & I
\end{array}\right),
$$

cujos elementos são definidos por

$$
\begin{aligned}
& \Delta_{j}=\left(I-A_{j j}\right)^{-1}, \\
& \Delta_{r}=\left(I-A_{r r}\right)^{-1}, \\
& \Delta_{j j}=\left(I-\Delta_{j} A_{j r} \Delta_{r} A_{r j}\right)^{-1}, \\
& \Delta_{r r}=\left(I-\Delta_{r} A_{r j} \Delta_{j} A_{j r}\right)^{-1} .
\end{aligned}
$$

Conjugando a equação (2.5) com a formulação de Leontief, dada por

$$
X=(I-A)^{-1} Y
$$

é possível derivar um conjunto de índices que podem ser usados tanto para ordenar os setores, em termos de sua importância no valor da produção gerado, quanto para verificar como ocorre o processo de produção na economia. Esses índices são obtidos por

$$
\left(\begin{array}{c}
X_{j} \\
X_{r}
\end{array}\right)=\left(\begin{array}{cc}
\Delta_{j j} & 0 \\
0 & \Delta_{r r}
\end{array}\right)\left(\begin{array}{cc}
\Delta_{j} & 0 \\
0 & \Delta_{r}
\end{array}\right)\left(\begin{array}{cc}
I & A_{j r} \Delta_{r} \\
A_{r j} \Delta_{j} & I
\end{array}\right)\left(\begin{array}{l}
Y_{j} \\
Y_{r}
\end{array}\right) .
$$

Pelo produto dos três últimos termos do lado direito da equação (2.11), chega-se a

$$
\left(\begin{array}{c}
X_{j} \\
X_{r}
\end{array}\right)=\left(\begin{array}{cc}
\Delta_{j j} & 0 \\
0 & \Delta_{r r}
\end{array}\right)\left(\begin{array}{c}
\Delta_{j} Y_{j}+\Delta_{j} A_{j r} \Delta_{r} Y_{r} \\
\Delta_{r} A_{r j} \Delta_{j} Y_{j}+\Delta_{\mathrm{r}} Y_{r}
\end{array}\right),
$$


do qual se podem extrair as novas definições de índice puro de ligação para trás $(P B L)$ e de índice puro de ligação para frente $(P F L)$, dadas por

$$
\begin{gathered}
P B L=\Delta_{r} A_{r j} \Delta_{j} Y_{j}, \\
P F L=\Delta_{j} A_{j r} \Delta_{r} Y_{r} .
\end{gathered}
$$

O $P B L$ representa o impacto puro do valor da produção total da região $j$ na região $r,\left(\Delta_{j} \mathrm{Y}_{j}\right)$, ou seja, o impacto que é livre da demanda de insumos que a região $j$ realiza da próprio região $j$ e dos retornos da região $r$ para a região $j$ e vice-versa. $O P F L$ indica o impacto puro do valor da produção total da região $r$ na região $j,\left(\Delta_{r} \mathrm{Y}_{r}\right)$. Como o $P B L$ e o $P F L$ são expressos em valores correntes, o índice puro do total das ligações $(P T L)$ de cada setor na economia pode ser obtido pela adição de ambos:

$P T L=P B L+P F L$.

\subsection{Os multiplicadores ${ }^{5}$}

Os multiplicadores complementam a análise da importância de determinado setor na economia, na medida em que são instrumentos úteis empregados na verificação de impactos em determinado sistema econômico, resultante de choques nos elementos exógenos, no curto ou longo prazo.

Qualquer que seja o tipo de análise e o prazo considerado, o modelo de insumo-produto para análise de impacto ou previsão segue a forma geral $X=(I-A)^{-1} Y$, em que $X$ é o valor da produção; $(I-A)^{-1}=L$, matriz inversa de Leontief, como definido anteriormente; e $Y$, demanda final (Miller e Blair, 1985).

\footnotetext{
Nesta seção, são descritos apenas os multiplicadores simples. Para outros tipos de multiplicadores, ver Miller e Blair (1985).
} 
Os multiplicadores de produção permitem determinar o impacto de variações na demanda final sobre o volume de produção. O multiplicador de produção simples, para o setor $j$, é definido pelo valor total da produção, em todos os setores da economia, necessário para satisfazer ao aumento de uma unidade monetária de demanda final pela produção do setor $j$. Em geral, o multiplicador de produção simples $\left(P_{j}\right)$, para o setor $j$, é dado por

$$
P_{j}=\sum_{\mathrm{i}=1}^{\mathrm{n}} l_{\mathrm{ij}}
$$

em que $l_{i j}$ representa os elementos da matriz inversa, de Leontief.

O multiplicador de renda $\left(O_{j}\right)$ permite determinar o impacto de variações na demanda final sobre a renda recebida pelas famílias. $O$ multiplicador de renda simples, para o setor $j$, é definido pela nova renda gerada em todos os setores da economia, resultante do aumento em uma unidade monetária de demanda final pelo produto do setor $j$. Assim, o multiplicador de renda simples pode ser expresso da seguinte forma:

$$
O_{j}=\sum_{\mathrm{i}=1}^{\mathrm{n}} a_{\mathrm{n}+1, \mathrm{i}} l_{i j}
$$

em que $a_{n+1, i}$ é um elemento da linha correspondente ao coeficiente da renda das famílias e $l_{i j}$, elementos da matriz inversa, de Leontief. 


\section{Resultados e discussão}

\subsection{Evolução da participação setorial}

Com vistas em dimensionar a participação dos setores na economia estadual, serão usados o valor adicionado (VA) e o valor da produção (VP), mostrados na Tabela 1. Observa-se que o setor Agropecuária apresentou a maior participação no VA e no VP, durante todo o período estudado, embora com participação decrescente e pequena reversão em 1995.

As posições seguintes foram alternadas entre alguns setores do ramo serviços (22 a 26), que apresentam crescimento da participação no VA e no VP e reforça a já conhecida tendência histórica registrada com o desenvolvimento das economias. Dentre eles, cabe destacar Serviços Industriais de Utilidade Pública, Comércio e Outros Serviços (Tabela $1)$.

Os setores componentes da indústria de transformação (3 a 21) apresentaram, de forma geral, crescimento da participação no VA e no VP, nos anos de 1980 e 1985, e redução nos anos de 1990 e 1995, notadamente devido à grande queda sofrida na participação dos setores da indústria alimentar.

A indústria alimentar que, neste estudo, engloba os setores 14 a 20, permaneceu como importante segmento da economia paranaense em 1980 e 1985, detendo cerca de 6,3\% e 14,3\%, em média, do VA e do VP, respectivamente, participações que lhe conferiu o primeiro lugar no segmento industrial (Tabela 1). 
Tabela 1 - Participação setorial no valor da produção (VP) e no valor adicionado (VA) do Paraná, 1980, 1985, 1990 e 1995 (Em \%)

\begin{tabular}{|c|c|c|c|c|c|c|c|c|c|}
\hline & \multirow[b]{2}{*}{ Setores } & \multicolumn{2}{|c|}{1980} & \multicolumn{2}{|c|}{1985} & \multicolumn{2}{|c|}{1990} & \multicolumn{2}{|c|}{1995} \\
\hline & & VP & VA & VP & VA & VP & VA & VP & VA \\
\hline$\overline{1}$ & Agropecuária & 17,12 & 22,69 & 16,00 & 20,17 & 12,97 & 14,11 & 13,97 & 15,49 \\
\hline 2 & Extrativa Mineral & 0,14 & 0,19 & 0,24 & 0,33 & 0,62 & 0,59 & 0,27 & 0,24 \\
\hline 3 & Fab. de Minerais não-Metálicos & 1,69 & 1,59 & 1,42 & 1,10 & 1,63 & 1,23 & 1,18 & 0,94 \\
\hline 4 & Metalurgia e Mecânica & 2,27 & 1,61 & 2,09 & 1,64 & 3,50 & 2,59 & 2,49 & 2,08 \\
\hline 5 & Material Elétrico/Eletrônico & 0,79 & 0,65 & 1,24 & 1,03 & 2,31 & 1,64 & 2,41 & 1,63 \\
\hline 6 & Material de Transporte & 0,61 & 0,36 & 1,24 & 0,78 & 3,02 & 1,63 & 3,34 & 1,94 \\
\hline 7 & Madeira e Mobiliário & 4,96 & 4,17 & 2,90 & 2,49 & 3,52 & 2,55 & 2,82 & 2,18 \\
\hline 8 & Celulose, Papel e Gráfica & 1,96 & 1,61 & 2,29 & 1,90 & 2,79 & 1,59 & 3,26 & 11,93 \\
\hline 9 & Indústria da Borracha & 0,17 & 0,08 & 0,14 & 0,10 & 0,14 & 0,09 & 0,04 & 0,02 \\
\hline 10 & Química e Farmacêutica & 7,11 & 3,58 & 8,55 & 4,29 & 5,00 & 3,07 & 4,18 & 2,91 \\
\hline 11 & Indústria de Artigos de Plásticos & 0,46 & 0,37 & 0,46 & 0,37 & 0,72 & 0,61 & 0,49 & 0,38 \\
\hline 12 & Indústria Têxtil & 1,75 & 1,16 & 2,04 & 1,42 & 1,62 & 1,01 & 0,91 & 0,47 \\
\hline 13 & Vestuário, Calçados, Couros e Peles & 0,50 & 0,41 & 0,73 & 0,62 & 1,60 & 1,10 & 1,06 & 0,71 \\
\hline 14 & Indústria do Café & 2,64 & 0,77 & 2,58 & 0,89 & 0,44 & 0,17 & 0,24 & 0,11 \\
\hline 15 & Beneficiamento de Produtos Vegetais & 3,27 & 1,87 & 2,89 & 1,76 & 1,45 & 0,69 & 1,10 & 0,47 \\
\hline 16 & Abate de Animais & 0,91 & 0,28 & 1,72 & 0,53 & 0,90 & 0,28 & 1,04 & 0,38 \\
\hline 17 & Indústria de Laticínios & 0,40 & 0,10 & 0,34 & 0,13 & 0,19 & 0,07 & 0,20 & 0,07 \\
\hline 18 & Fabricação de Açúcar & 0,83 & 0,44 & 0,86 & 0,37 & 0,32 & 0,15 & 0,18 & 0,07 \\
\hline 19 & Fabricação de Óleos Vegetais & 2,91 & 0,90 & 3,35 & 1,15 & 1,03 & 0,31 & 0,82 & 0,23 \\
\hline \multirow[t]{2}{*}{20} & Fab. de Outros Produtos Alimentares & 2,88 & 1,80 & 2,99 & 1,54 & 1,32 & 0,66 & 1,93 & 1,00 \\
\hline & Total Indústria Alimentar & 13,84 & 6,16 & 14,73 & 6,37 & $\mathbf{5 , 6 5}$ & 2,33 & $\mathbf{5 , 5 1}$ & $\mathbf{2 , 3 3}$ \\
\hline 21 & Indústrias Diversas & 0,34 & 0,21 & 0,32 & 0,31 & 0,80 & 0,74 & 0,83 & 0,68 \\
\hline 22 & Serviços Ind. de Utilidade Pública & 1,37 & 1,56 & 3,67 & 3,60 & 5,19 & 4,76 & 6,27 & 6,20 \\
\hline 23 & Construção Civil & 9,63 & 8,24 & 6,17 & 5,10 & 7,90 & 6,89 & 7,61 & 7,87 \\
\hline 24 & Comércio & 6,83 & 8,93 & 8,96 & 12,13 & 11,42 & 13,81 & 10,15 & 11,33 \\
\hline 25 & Transportes & 4,02 & 4,22 & 5,66 & 5,20 & 5,22 & 4,73 & 4,80 & 4,21 \\
\hline \multirow[t]{2}{*}{26} & Outros Serviços & 24,42 & 32,18 & 21,13 & 31,06 & 24,36 & 34,94 & 28,41 & 36,44 \\
\hline & Total Paraná & 100,00 & 100,00 & 100,00 & 100,00 & 100,00 & 100,00 & 100,00 & 100,00 \\
\hline
\end{tabular}

Fonte: Estimativa dos autores.

Por outro lado, nos anos de 1990 e 1995, a participação da indústria alimentar no VA e no VP decresceu expressivamente (Tabela 1). Podemse considerar como causas prováveis dessa queda a diversificação da indústria paranaense e o menor dinamismo dos setores alimentares, notadamente dos mais tradicionais, como Indústria do Café e Beneficiamento de Produtos Vegetais. A diversificação da indústria pode ser constatada, principalmente, pelo aumento da participação no VA e no VP dos setores Metalurgia e Mecânica, Material Elétrico/Eletrônico, Material de Transporte e Celulose, Papel e Gráfica. 
De fato, a indústria de transformação, exclusive a indústria alimentar, aumentou sua participação no VA e no VP, de 1985 para 1990, a exemplo dos setores do ramo Serviços. Entretanto, de 1990 para 1995, enquanto o setor Agropecuária e os relacionados com a indústria alimentar mostraram ligeira recuperação e os setores componentes do ramo serviços reforçaram sua participação crescente no VA e no VP, os demais setores da indústria de transformação tiveram, de forma geral, comportamento inverso (Tabela 1).

O período de 1990 a 1995 mostrou, assim, outra realidade para a economia estadual, quando comparado com o de 1980 a 1985. De 1985 a 1995, houve queda drástica na participação no VA e no VP dos setores da indústria alimentar e da Agropecuária. Os setores alimentares mais tradicionais, a exemplo da Indústria do Café e Beneficiamento de Produtos Vegetais, tiveram as maiores quedas. No entanto, no mesmo período, houve ligeira recuperação na indústria alimentar, conduzida pelos setores Abate de Animais, Indústria de Laticínios e Fabricação de Outros Produtos Alimentares, considerados mais modernos e dinâmicos (Tabela 1).

\subsection{Estrutura produtiva do Paraná}

\subsubsection{Relações intersetoriais e setores-chave}

A determinação de setores-chave na economia não é tarefa fácil, dado que nem todo setor será capaz de cumprir todas as funções desejáveis, isto é, possuir os maiores índices de ligações para frente e para trás, gerar grande valor de produção, ser importante fonte geradora de emprego e renda, permitir a melhor distribuição de renda e produzir o menor nível de poluição, etc. ${ }^{6}$

Nessa seção são usadas duas medidas para determinar os setores-chave na economia paranaense, no período em estudo. A primeira tem como base os índices de Rasmussen-Hirschman para frente e para trás, que

Uma boa discussão sobre o que é setor-chave pode ser encontrada em McGilvray (1977). 
levam em consideração como os setores se relacionam uns com os outros, no que concerne aos coeficientes técnicos; a segunda se refere aos índices puros de ligações, que, além da estrutura produtiva interna, levam também em consideração a importância dos setores na geração do valor da produção na economia.

Para os índices de Rasmussen-Hirschman, os setores-chave foram definidos de acordo com o critério restrito dado por McGilvray (1977), isto é, setor-chave é aquele que apresenta, simultaneamente, valores maiores do que um para as ligações para trás e para frente. Considerando os índices puros, setor-chave para a economia é aquele que apresenta valor maior do que um para o índice puro total normalizado. ${ }^{7}$

Os índices de Rasmussen-Hirschman e Puro são apresentados nas Tabelas 2 e 3, respectivamente, e o sumário dos resultados está exposto no Quadro 1. Os setores definidos como chaves, segundo o índice de Rasmussen-Hirschman, foram Celulose, Papel e Gráfica (8) e Têxtil (12), este último nos anos de 1980, 1985 e 1990.

Entretanto, uma forma mais abrangente de visualizar a evolução do perfil da estrutura produtiva paranaense é considerar a definição menos restrita de setores-chave, segundo a qual os índices para frente ou para trás, maiores do que 1 , indicam setores dinâmicos e, portanto, importantes para o crescimento da economia. Nesta perspectiva, o Paraná apresentou, além dos setores assinalados anteriormente, 14 setores-chave em 1980; 16 em 1985; 18 em 1990; e 15 em 1995 (Tabela 2).

Deve ser reforçado que a definição de setor-chave, em certo sentido, depende de como os setores são agregados nas matrizes insumo-produto, de forma que diferentes agregações podem resultar em diferentes setores-chave para dada economia. 
Tabela 2 - Índices de ligações de Rasmussen-Hirschman, para trás (T) e para frente (F), Paraná, 1980, 1985, 1990, e 1995

\begin{tabular}{|c|c|c|c|c|c|c|c|c|c|}
\hline \multicolumn{2}{|c|}{ Setores } & \multicolumn{2}{|c|}{1980} & \multicolumn{2}{|c|}{1985} & \multicolumn{2}{|c|}{1990} & \multicolumn{2}{|c|}{1995} \\
\hline & & $\mathrm{T}$ & $\mathrm{F}$ & $\mathrm{T}$ & $\mathrm{F}$ & $\mathrm{T}$ & F & $\mathrm{T}$ & $\mathrm{F}$ \\
\hline 1 & Agropecuária & 0,899 & 3,138 & 0,898 & 3,088 & 0,855 & 2,851 & 0,880 & 3,081 \\
\hline 2 & Extrativa Mineral & 0,789 & 0,596 & 0,743 & 0,644 & 0,869 & 0,731 & 0,907 & 0,693 \\
\hline 3 & Fab. de Minerais não-Metálicos & 0,961 & 0,837 & 1,020 & 0,876 & 1,026 & 0,905 & 1,021 & 0,900 \\
\hline 4 & Metalurgia e Mecânica & 0,787 & 0,883 & 0,766 & 0,856 & 0,866 & 1,229 & 0,819 & 1,025 \\
\hline 5 & Material Elétrico/Eletrônico & 0,799 & 0,621 & 0,804 & 0,666 & 0,933 & 0,797 & 0,914 & 0,772 \\
\hline 6 & Material de Transporte & 0,784 & 0,609 & 0,805 & 0,676 & 1,049 & 0,904 & 0,990 & 0,888 \\
\hline 7 & Madeira e Mobiliário. & 1,071 & 0,806 & 1,027 & 0,758 & 1,059 & 0,769 & 1,063 & 0,787 \\
\hline 8 & Celulose, Papel e Gráfica & 1,084 & 1,031 & 1,069 & 1,067 & 1,168 & 1,156 & 1,164 & 1,142 \\
\hline 9 & Indústria da Borracha & 0,951 & 0,632 & 0,877 & 0,616 & 0,862 & 0,616 & 0,847 & 0,623 \\
\hline 10 & Química e Farmacêutica & 0,856 & 2,612 & 0,904 & 2,897 & 0,911 & 2,059 & 0,913 & 1,812 \\
\hline 11 & Indústria de Artigos de Plásticos & 1,025 & 0,681 & 1,051 & 0,681 & 0,923 & 0,788 & 0,938 & 0,760 \\
\hline 12 & Indústria Têxtil & 1,075 & 1,049 & 1,110 & 1,135 & 1,041 & 1,106 & 1,017 & 0,991 \\
\hline 13 & Vestuário, Calçados, Couros e Peles & 0,979 & 0,575 & 0,994 & 0,588 & 1,032 & 0,619 & 0,998 & 0,654 \\
\hline 14 & Indústria do Café & 1,608 & 0,822 & 1,409 & 0,721 & 1,304 & 0,701 & 0,992 & 0,693 \\
\hline 15 & Benef. de Produtos Vegetais & 1,159 & 0,710 & 1,077 & 0,730 & 1,138 & 0,698 & 1,152 & 0,710 \\
\hline 16 & Abate de Animais & 1,306 & 0,612 & 1,331 & 0,652 & 1,250 & 0,620 & 1,288 & 0,683 \\
\hline 17 & Indústria de Laticínios & 1,285 & 0,664 & 1,204 & 0,647 & 1,110 & 0,596 & 1,158 & 0,644 \\
\hline 18 & Fabricação de Açúcar & 1,021 & 0,732 & 1,155 & 0,765 & 1,078 & 0,660 & 1,166 & 0,667 \\
\hline 19 & Fabricação de Óleos Vegetais & 1,304 & 0,764 & 1,329 & 0,812 & 1,317 & 0,792 & 1,365 & 0,839 \\
\hline 20 & Fab. de Outros Produtos Alimentares & 1,172 & 0,830 & 1,233 & 0,722 & 1,173 & 0,677 & 1,165 & 0,760 \\
\hline 21 & Indústrias Diversas & 0,819 & 0,616 & 0,850 & 0,622 & 0,904 & 0,733 & 0,968 & 0,711 \\
\hline 22 & Serviços Ind.de Utilidade Pública & 0,893 & 0,938 & 0,987 & 1,109 & 0,900 & 1,189 & 0,918 & 1,230 \\
\hline 23 & Construção Civil & 0,928 & 0,659 & 0,903 & 0,648 & 0,888 & 0,644 & 0,844 & 0,685 \\
\hline 24 & Comércio & 0,808 & 1,092 & 0,810 & 1,383 & 0,789 & 1,449 & 0,845 & 1,415 \\
\hline 25 & Transporte & 0,804 & 1,045 & 0,888 & 1,207 & 0,836 & 1,200 & 0,873 & 1,172 \\
\hline 26 & Outros Serviços & 0,835 & 2,448 & 0,756 & 1,437 & 0,722 & 1,514 & 0,798 & 1,666 \\
\hline
\end{tabular}

Fonte: Estimativa dos autores.

Essas informações evidenciaram as seguintes características da economia paranaense no período: a) A conjugação de índices de ligações para trás elevados, em todos os setores alimentares, com índices de ligações para frente mais elevados nos setores Agropecuária, Serviços e Química e Farmacêutica permitiu afirmar que o Paraná ainda apresentava, no período, indústria pouco diversificada, centrada nas indústrias produtoras de alimentos e na agropecuária enquanto fornecedora de matérias-primas; b) O número de setores com ligações para trás foi, praticamente, o dobro do número de setores com ligações para frente, o que evidencia que são aceitáveis políticas que objetivem estimular a demanda de insumos intermediários, notadamente se essa demanda for atendida por insumos domésticos; c) O comportamento dos índices de ligações para trás dos setores alimentares apontou na direção de queda na importância dos mais tradicionais, como Indústria do Café e Beneficiamento de Produtos 
Vegetais, como setores indutores do crescimento da economia estadual; d) Os setores alimentares mais modernos ou com novas atividades registraram menor decréscimo, a exemplo de Abate de Animais, Indústria de Laticínios e Fabricação de Outros Produtos Alimentares, ou mesmo crescimento no seu dinamismo, como foi o caso de Fabricação de Açúcar e Fabricação de Óleos Vegetais; e) Outros setores da indústria de transformação, tais como Metalurgia e Mecânica, Material de Transporte e, em menor grau, Material Elétrico/Eletrônico emergiram na economia paranaense, delineando tendência futura de maior diversificação industrial; f) Alguns setores do ramo serviços ganharam importância para a economia estadual.

Considerando, exclusivamente, os índices puros, os seguintes setores foram considerados chave em todos ou em alguns anos do período: Agropecuária; Metalurgia e Mecânica (somente em 1990); Madeira e Mobiliário (em 1980 e 1990); Celulose, Papel e Gráfica (somente em 1995); Química e Farmacêutica; Indústria do Café; Beneficiamento de Produtos Vegetais; Fabricação de Óleos Vegetais e Fabricação de Outros Produtos Alimentares (em 1980 e 1985); Serviços Industriais de Utilidade Pública (em 1990 e 1995); Construção Civil; Comércio; Transporte e Outros Serviços (Tabela 3).

Observou-se que, dependendo do critério utilizado, houve diferença na classificação dos setores-chave. No conceito de Rasmussen-Hirschman, setor-chave significa um setor importante em estrutura produtiva, enquanto nos índices puros, quer dizer que o setor se sobressai no processo de geração de produção. Desse modo, o setor classificado como chave, em ambas as abordagens, é, certamente, muito importante na economia do Paraná, razão por que, ao levar em consideração as políticas econômicas adotadas, o impacto nesses setores deve ser bem avaliado, uma vez que pode ter profundo reflexo na economia do Estado. 
Tabela 3 - Índices Puros Normalizados, Paraná, 1980, 1985, 1990, e 1995

\begin{tabular}{|c|c|c|c|c|c|c|c|c|c|c|c|c|c|}
\hline \multicolumn{2}{|r|}{ Setores } & \multicolumn{3}{|c|}{1980} & \multicolumn{3}{|c|}{1985} & \multicolumn{3}{|c|}{1990} & \multicolumn{3}{|c|}{1995} \\
\hline & & Trás & Frente & Total & Trás & Frente & Total & Trás & Frente & Total & Trás & Frente & Total \\
\hline 1 & Agropecuária & 3,13 & 5,31 & 4,22 & 2,63 & 5,72 & 4,17 & 2,93 & 2,89 & 2,91 & 2,92 & 3,40 & 3,16 \\
\hline 2 & Extrativa Mineral & 0,02 & 0,07 & 0,05 & 0,01 & 0,19 & 0,10 & 0,10 & 0,40 & 0,25 & 0,05 & 0,21 & 0,13 \\
\hline 3 & Fab. de Minerais não-Metálicos & 0,04 & 1,29 & 0,66 & 0,15 & 0,88 & 0,51 & 0,14 & 1,24 & 0,69 & 0,13 & 1,03 & 0,58 \\
\hline 4 & Metalurgia e Mecânica & 0,35 & 0,58 & 0,46 & 0,30 & 0,54 & 0,42 & 0,57 & 1,48 & 1,02 & 0,42 & 1,14 & 0,78 \\
\hline 5 & Material Elétrico/Eletrônico & 0,18 & 0,14 & 0,16 & 0,26 & 0,22 & 0,24 & 0,61 & 0,65 & 0,63 & 0,77 & 0,55 & 0,66 \\
\hline 6 & Material de Transporte & 0,14 & 0,09 & 0,11 & 0,23 & 0,24 & 0,23 & 0,83 & 0,73 & 0,78 & 0,90 & 0,72 & 0,81 \\
\hline 7 & Madeira e Mobiliário, & 1,94 & 0,55 & 1,25 & 1,13 & 0,33 & 0,73 & 1,71 & 0,47 & 1,09 & 1,45 & 0,45 & 0,95 \\
\hline 8 & Celulose, Papel e Gráfica & 0,25 & 1,01 & 0,63 & 0,33 & 1,11 & 0,72 & 0,65 & 1,29 & 0,96 & 0,98 & 1,40 & 1,19 \\
\hline 9 & Indústria da Borracha & 0,04 & 0,07 & 0,06 & 0,03 & 0,07 & 0,05 & 0,02 & 0,10 & 0,06 & 0,01 & 0,03 & 0,02 \\
\hline 10 & Química e Farmacêutica & 0,12 & 5,12 & 2,62 & 0,27 & 5,89 & 3,07 & 0,12 & 4,29 & 2,20 & 0,29 & 3,71 & 2,00 \\
\hline 11 & Indústria de Artigos de Plásticos & 0,03 & 0,34 & 0,18 & 0,07 & 0,31 & 0,19 & 0,00 & 0,68 & 0,34 & 0,04 & 0,49 & 0,26 \\
\hline 12 & Indústria Têxtil & 0,41 & 0,47 & 0,44 & 0,46 & 0,56 & 0,51 & 0,27 & 0,79 & 0,52 & 0,20 & 0,47 & 0,33 \\
\hline 13 & Vest., Calçados, Couros e Peles & 0,28 & 0,02 & 0,15 & 0,42 & 0,02 & 0,22 & 1,06 & 0,07 & 0,57 & 0,66 & 0,04 & 0,35 \\
\hline 14 & Indústria do Café & 2,06 & 0,04 & 1,05 & 2,07 & 0,04 & 1,06 & 0,34 & 0,02 & 0,18 & 0,11 & 0,02 & 0,07 \\
\hline 15 & Benef. De Produtos Vegetais & 2,19 & 0,35 & 1,27 & 1,61 & 0,50 & 1,06 & 1,09 & 0,26 & 0,67 & 0,86 & 0,27 & 0,56 \\
\hline 16 & Abate de Animais & 0,76 & 0,13 & 0,45 & 1,52 & 0,15 & 0,84 & 0,82 & 0,12 & 0,47 & 1,03 & 0,14 & 0,59 \\
\hline 17 & Indústria de Laticínios & 0,28 & 0,04 & 0,16 & 0,22 & 0,03 & 0,13 & 0,15 & 0,02 & 0,08 & 0,17 & 0,02 & 0,09 \\
\hline 18 & Fabricação de Açúcar & 0,25 & 0,23 & 0,24 & 0,32 & 0,25 & 0,29 & 0,15 & 0,10 & 0,12 & 0,12 & 0,06 & 0,09 \\
\hline 19 & Fabricação de Óleos Vegetais & 2,04 & 0,30 & 1,17 & 2,22 & 0,41 & 1,32 & 0,63 & 0,27 & 0,45 & 0,50 & 0,35 & 0,42 \\
\hline 20 & Fab. de Outros Prod. Alimentares & 1,17 & 1,10 & 1,14 & 2,00 & 0,63 & 1,32 & 0,74 & 0,53 & 0,63 & 1,15 & 0,82 & 0,98 \\
\hline 21 & Indústrias Diversas & 0,08 & 0,11 & 0,09 & 0,07 & 0,13 & 0,10 & 0,20 & 0,42 & 0,31 & 0,29 & 0,38 & 0,34 \\
\hline 22 & Serviços Ind, de Utilidade Pública & 0,12 & 0,62 & 0,37 & 0,49 & 0,89 & 0,69 & 0,87 & 1,37 & 1,12 & 0,73 & 1,51 & 1,11 \\
\hline 23 & Construção Civil & 4,23 & 0,46 & 2,35 & 2,56 & 0,28 & 1,42 & 3,77 & 0,37 & 2,07 & 2,91 & 0,40 & 1,65 \\
\hline 24 & Comércio & 1,40 & 2,16 & 1,78 & 1,91 & 2,61 & 2,26 & 2,99 & 2,81 & 2,90 & 3,02 & 3,05 & 3,03 \\
\hline 25 & Transporte & 0,53 & 1,84 & 1,19 & 1,40 & 1,78 & 1,59 & 1,27 & 1,86 & 1,56 & 1,26 & 1,93 & 1,60 \\
\hline 26 & Outros Serviços & 3,99 & 3,55 & 3,77 & 3,32 & 2,22 & 2,77 & 3,98 & 2,79 & 3,39 & 5,04 & 3,43 & 4,24 \\
\hline
\end{tabular}

Fonte: Estimativa dos autores. 
A consolidação dos setores-chave na economia paranaense está apresentada no Quadro 1. Por ambos os critérios, os seguintes setores foram considerados chave, em todos os anos ou em alguns anos do período: Agropecuária; Metalurgia e Mecânica (somente em 1990); Madeira e Mobiliário (em 1980 e 1990); Celulose, Papel e Gráfica; Química e Farmacêutica; Têxtil (exceto em 1995); Indústria do Café, Beneficiamento de Produtos Vegetais, Fabricação de Óleos Vegetais e Fabricação de Outros Produtos Alimentares (em 1980 e 1985); Serviços Industriais de Utilidade Pública (em 1990 e 1995); Construção Civil; Comércio, Transporte e Outros Serviços. 
Quadro 1 - Setores-chave consolidados, índices de Rasmussen/ Hirschman e Puro, Paraná, 1980, 1985, 1990 e 1995

\begin{tabular}{|c|c|c|c|c|c|}
\hline & Setores & 1980 & 1985 & 1990 & 1995 \\
\hline 1 & Agropecuária & (-) & (-) & (2) & (2) \\
\hline 2 & Extrativa Mineral & & & & \\
\hline 3 & Fabricação de Minerais não-Metálicos & & & & \\
\hline 4 & Metalurgia e Mecânica & & & (2) & \\
\hline 5 & Material Elétrico/Eletrônico & & & & \\
\hline 6 & Material de Transporte & & & & \\
\hline 7 & Madeira e Mobiliário. & (2) & & (-) & \\
\hline 8 & Celulose, Papel e Gráfica & $\theta$ & $\theta$ & $\theta$ & $\oplus$ \\
\hline 9 & Indústria da Borracha & & & & \\
\hline 10 & Química e Farmacêutica & (2) & (2) & (-) & (?) \\
\hline 11 & Indústria de Artigos de Plásticos & & & & \\
\hline 12 & Indústria Têxtil & $\theta$ & $\theta$ & $\theta$ & \\
\hline 13 & Vestuário, Calçados, Couros e Peles & & & & \\
\hline 14 & Indústria do Café & (-) & (-) & & \\
\hline 15 & Beneficiamento de Produtos Vegetais & (-) & (-) & & \\
\hline 16 & Abate de Animais & & & & \\
\hline 17 & Indústria de Laticínios & & & & \\
\hline 18 & Fabricação de Açúcar & & & & \\
\hline 19 & Fabricação de Óleos Vegetais & (2) & (2) & & \\
\hline 20 & Fabricação de Outros Produtos Alimentares & (2) & (2) & & \\
\hline 21 & Indústrias Diversas & & & & \\
\hline 22 & Serviços Industriais de Utilidade Pública & & & (-) & (๑) \\
\hline 23 & Construção Civil & (2) & (2) & (-) & (-) \\
\hline 24 & Comércio & (2) & (2) & (2) & (2) \\
\hline 25 & Transporte & (-) & (-) & (-) & (๑) \\
\hline 26 & Outros Serviços & (2) & (2) & (-) & (2) \\
\hline
\end{tabular}

Fonte: Tabelas 2 e 3.

- Setor-chave pela abordagem de Rasmussen/Hirschman (ligações para frente e para trás maiores do que 1 ).

() Setor-chave pela abordagem do Índice Puro (Índice Puro Total normalizado maior do que 1).

$\oplus$ Setor-chave por ambas as abordagens, Rasmussen/Hirschman e Índice Puro.

\subsubsection{Estrutura Produtiva ao longo do tempo}

A partir dos índices de Rasmussen-Hirschman e puro e tomando o ano de 1980 como numerário, foi possível verificar como a estrutura produtiva da economia estadual mudou ao longo do tempo. 
Para mostrar essa alteração foram geradas as Figuras 2 a 5, que se assemelham aos eletroencefalogramas da medicina, que medem as diferenças a partir de dado padrão. Ao fazer essa analogia, essas figuras são chamadas de Eletroeconogramas da Estrutura Produtiva (EEP), originalmente definidas em Guilhoto et al. (2001). A idéia geral é que, quanto menor a mudança retratada pela dispersão das figuras, mais próximos os resultados estariam dos encontrados para o ano-base (1980); inversamente, quanto maior a dispersão das figuras, maiores as mudanças ocorridas na estrutura produtiva ao longo do período em análise.

Em geral, as mudanças retratadas pelos índices de Rasmussen-Hirschman (Figuras 2 e 3 ) foram menores do que as mostradas pelos índices puros (Figuras 4 e 5), reflexo das alterações mais lentas na tecnologia de produção. As dispersões reveladas por ambos os índices também foram, em geral, maiores no período de 1980 a 1990 e no período 1980 a 1995, do que nos outros, o que mostra que as mudanças ocorreram na economia ao longo do tempo.

Para os índices de Rasmussen-Hirschman, as maiores dispersões foram encontradas para as ligações para frente, enquanto para os índices puros elas foram observadas em ambas as ligações.

Os setores que mostraram as maiores dispersões, isto é, as estruturas setoriais que passaram pelas maiores mudanças no período, considerando as ligações de Rasmussen-Hirschman para frente, foram Metalurgia e Mecânica, Material de Transporte, Serviços Industriais de Utilidade Pública, Comércio, Química e Farmacêutica e Serviços (Figura 3).

Levando em consideração as ligações para trás, de Hirschman/ Rasmussen, os setores que mais se destacaram foram Material de Transporte, Fabricação de Açúcar, Indústrias Diversas, Indústria do Café e Indústria de Laticínios (Figuras 2). 
Rossana Lott Rodrigues, Antonio Carlos Moretto \& José Joaquim Martins Guilhoto



Figura 2 - Eletroeconograma das Mudanças nos Índices de Hirschman/ Rasmussen para trás, Paraná, 1980 a 1995.

Fonte: Tabela 2 .

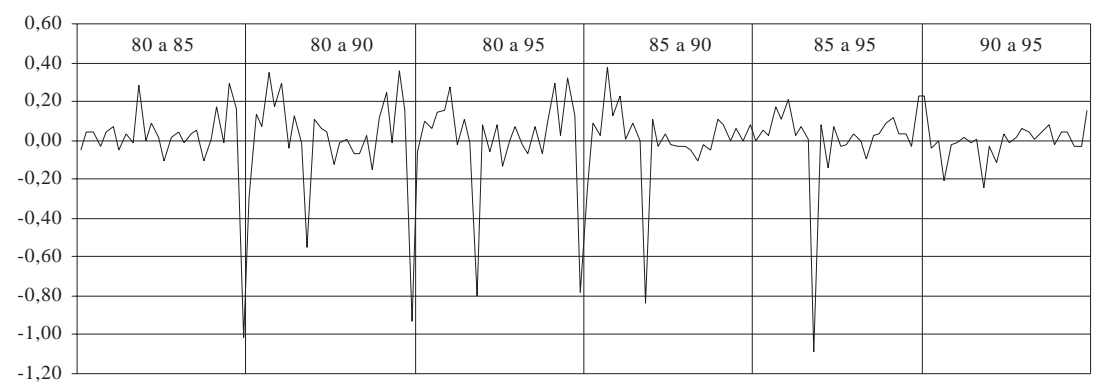

Figura 3 - Eletroeconograma das Mudanças nos Índices de Hirschman/ Rasmussen para frente, Paraná, 1980 a 1995.

Fonte: Tabela 3. 


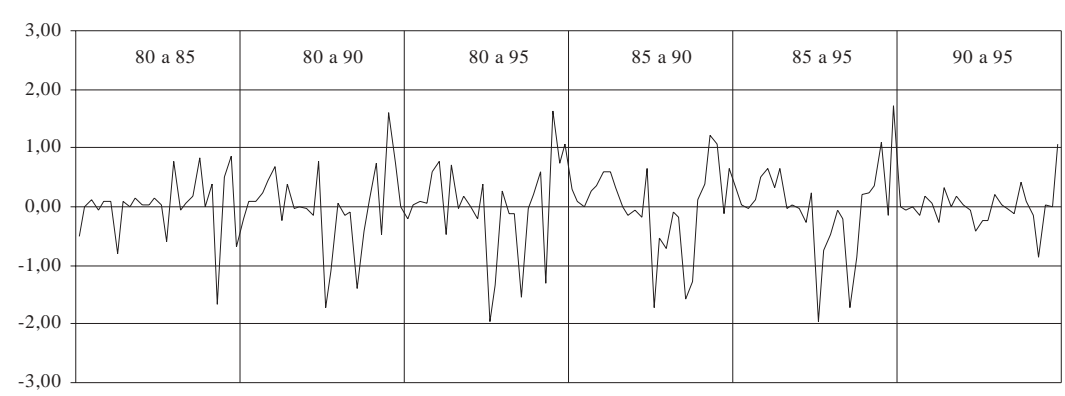

Figura 4 - Eletroeconograma das Mudanças nos Índices Puros Normalizados para trás, Paraná, 1985 a 1995.

Fonte: Tabela 3.

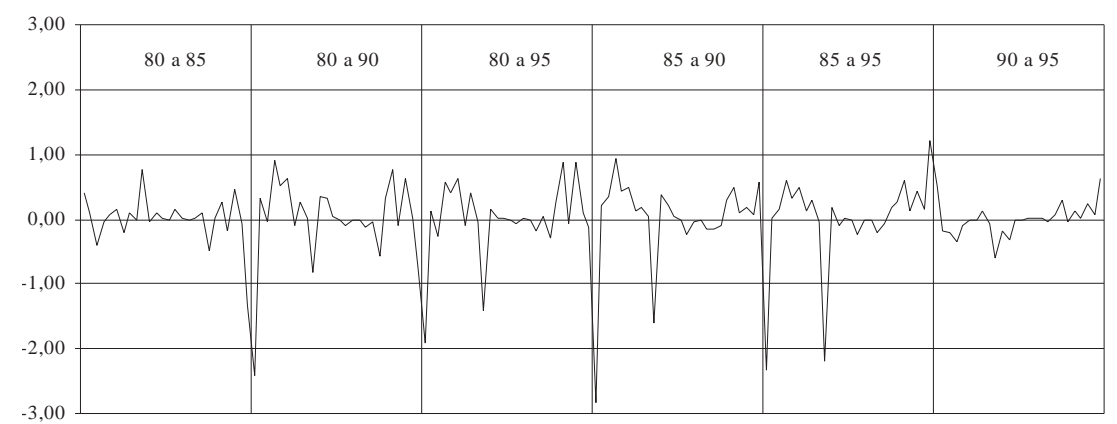

Figura 5 - Eletroeconograma das Mudanças nos Índices Puros Fonte: Tabela 4.

Normalizados para frente, Paraná, 1985 a 1995.

Considerando o índice puro total (Figura 6), as maiores mudanças foram detectadas nos setores Agropecuária, Indústria do Café, Beneficiamento de Produtos Vegetais, Fabricação de Óleos Vegetais, Fabricação de Outros Produtos Alimentares, Metalurgia e Mecânica, Material de Transporte, Serviços Industriais de Utilidade Pública e Comércio. 


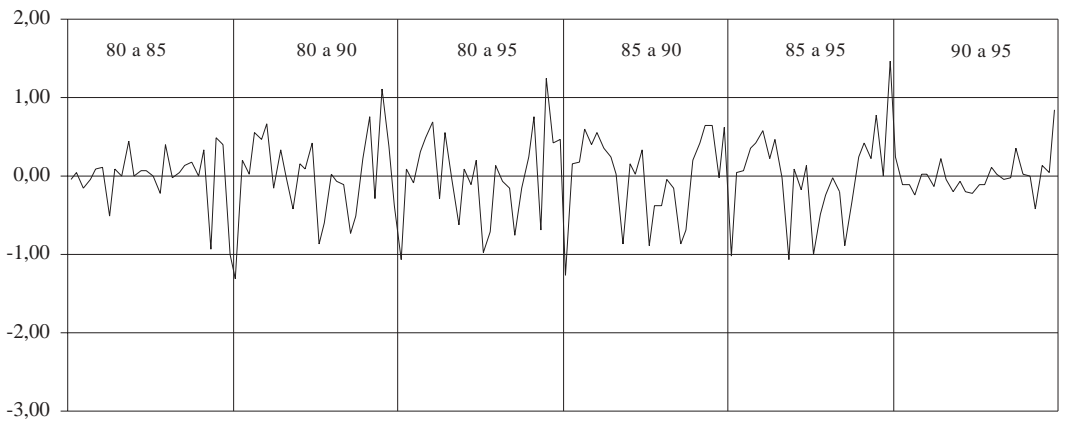

Figura 6 - Eletroeconograma das Mudanças nos Índices Puros Normalizados Totais, Paraná, 1985 a 1995.

Fonte: Tabela 4.

3.1.3. Multiplicadores da produção e da renda dos setores alimentares

As matrizes de insumo-produto construídas permitem verificar como se modificam a produção e a renda na economia, quando a demanda final de um setor se altera.

Para examinar este impacto nos setores da Indústria Alimentar, implementou-se o aumento de $\mathrm{R} \$ 1000,00$ nas suas demandas finais e, a partir daí, com base na matriz inversa de Leontief e nos coeficientes de remuneração, foram obtidos os efeitos sobre produção e renda. Esses resultados estão na Tabela 5. 
Tabela 5 -Produção e renda induzidas pelo aumento de $\mathrm{R} \$ 1000,00$ na demanda final, Paraná, 1980, 1985, 1990 e 1995 (Em R\$)

\begin{tabular}{lcccccccc}
\hline \multicolumn{1}{c}{ Setores } & \multicolumn{2}{c}{1980} & \multicolumn{2}{c}{1985} & \multicolumn{2}{c}{1990} & \multicolumn{2}{c}{1995} \\
\cline { 2 - 8 } & Produção & Renda & Produção & Renda & Produção & Renda & Produção & Renda \\
\hline 1. Indústria do Café & 2.879 & 258 & 2.496 & 203 & 2.359 & 232 & 1.641 & 123 \\
2. Benef. de Produtos Vegetais & 2.076 & 261 & 1.909 & 217 & 2.060 & 234 & 1.907 & 189 \\
3. Abate de Animais & 2.340 & 236 & 2.359 & 236 & 2.263 & 230 & 2.131 & 199 \\
4. Indústria de Laticínios & 2.301 & 242 & 2.134 & 207 & 2.009 & 183 & 1.916 & 153 \\
5. Fabricação de Açúcar & 1.829 & 199 & 2.047 & 215 & 1.951 & 223 & 1.929 & 222 \\
6. Fabricação de Óleos Vegetais & 2.335 & 229 & 2.355 & 205 & 2.384 & 207 & 2.259 & 167 \\
7. Fab. de Outros Prod. Alimentares & 2.100 & 292 & 2.186 & 281 & 2.123 & 281 & 1.927 & 231 \\
\hline
\end{tabular}

Fonte: estimativa dos autores.

Em 1980 e 1985, a Indústria do Café e Abate de Animais deteve os maiores aumentos na produção induzida pela demanda final; em 1990, essa posição ficou com os setores Indústria do Café e Fabricação de Óleos Vegetais; e em 1995, com Abate de Animais e Fabricação de Óleos Vegetais (Tabela 5). Isso ocorreu em razão da própria mudança na composição da produção agrícola na economia paranaense, no período. Assim, apesar de o café ter sido, durante muito tempo, o principal produto da economia estadual, chegando a responder por $62,8 \%$ da produção brasileira na safra 1962/63 (Padis, 1981), as fortes geadas e o processo de substituição de culturas, ocorrido a partir dos anos 70 , reduziram sua participação e impulsionaram a cultura da soja, que se transformou, então, no produto mais importante da agricultura do Estado.

Quanto ao impacto do aumento na demanda sobre a renda, o setor Fabricação de Outros Produtos Alimentares foi o que mais se destacou no período 1980/95. Uma constatação importante, que pôde ser feita a partir da análise dos dados da Tabela 5, é que quase todos os setores da indústria alimentar, exceto Fabricação de Açúcar, passaram a contribuir menos para a renda das famílias, o que indica menor participação do trabalho no processo produtivo, o qual se tornou mais capital-intensivo.

Finalmente, merece ser ressaltado que, de forma geral, a produção e a renda responderam, com menor intensidade, aos aumentos de demanda final nos setores em foco, ao longo do período analisado, o que reflete a queda na participação desses setores na economia estadual e indica que outros setores estão ganhando espaço no cenário paranaense. 


\section{Considerações finais}

O padrão de mudança da estrutura produtiva do Paraná, ao longo do período 1980-95, mostrou que os setores da indústria de transformação ligados ao processamento alimentar perderam importância relativa na economia paranaense, tanto no que se refere à geração dos valores da produção e adicionado, quanto no sentido das ligações com os demais setores. Além disso, a produção e a renda desses setores responderam menos aos impactos na demanda final, ao longo do período analisado.

Outras tendências que podem ser delineadas na estrutura produtiva do Estado foram maior diversificação e complexidade, com destaque para alguns setores do ramo serviços e outros emergentes da indústria de transformação.

Os resultados deste estudo, entendidos como indicadores do comportamento setorial da economia paranaense, constituem fonte importante de informação que poderá servir de orientação ao governo e aos empresários em suas decisões de política e investimentos.

Por fim, advoga-se a importância de se atualizarem as matrizes insumoproduto para o Paraná via construção e não por estimação, o que permitirá realizar estudos mais precisos que poderão, ou não, corroborar as tendências aqui apontadas.

\section{Referências}

CELLA, G. The input-output measurement of interindustry linkages. Oxford Bulletin of Economics and Statistics, v. 70, p. 705-712, 1984.

CLEMENTS, B. On the decomposition and normalization of interindustry linkages. Economics Letters, v. 33, p. 337-340, 1990. 
GUILHOTO, J. J. M.; SONIS, M.; HEWINGS, G. J. D.; MARTINS, E. B. Índices de ligações e setores-chave na economia brasileira: 1959/80. Pesquisa e Planejamento Econômico, v. 24, n. 2, p. 287-314, 1994.

GUILHOTO, J. J. M.; SONIS, M.; HEWINGS, G. J. D. "Linkages and multipliers in a multiregional framework: integrations of alternative approaches." Urbana: University of Illinois. Discussion Paper, 96-T-8 Regional Economics Applications Laboratory, 1996, 20p.

GUilhoto, J. J. M.; CROCOMO, F. C.; MORETTO, A. C.; RODRIGUES, R. L. Comparative analysis of Brazil's national and regional economic structure, 1985, 1990, 1995". In GUILHOTO, J. J. M. e G. J. D. HEWINGS (eds.) Structure and Structural Change in the Brazilian Economy. Aldershot: Ashgate. 2001, 390p.

HEWINGS, G. J. D. The empirical identification of key sectors in an economy: a regional perspective. The Developing Economies, v. 20, p. 173-195, 1982.

INSTITUTO PARANAENSE DE DESENVOLVIMENTO ECONÔMICO E SOCIAL. Estrutura produtiva paranaense. Análise Conjuntural, v.13, n.3, p.2-4, mar. 1991.

INSTITUTO PARANAENSE DE DESENVOLVIMENTO ECONÔMICO E SOCIAL. PIB do Paraná 1980-95. Curitiba: IPARDES, 1997a. 27p.

INSTITUTO PARANAENSE DE DESENVOLVIMENTO ECONÔMICO E SOCIAL. Produto Interno Bruto do Paraná: dados municipais - 1995. Curitiba: IPARDES, jul. 1998. 32p.

LOURENÇO, G. M. Evolução recente e perspectivas das economias regionais segundo a F.G.V. Análise Conjuntural, v.16, n.1-2, p.3-6, jan/ fev. 1994. 
LOURENÇO, G. M. Expansão recente da economia paranaense: componentes estruturais e conjunturais. Análise Conjuntural, v.17, n.34, p.20-25, mar/abr. 1995.

LOURENÇO, G. M. A produção industrial paranaense em 1995. Análise Conjuntural, v.18, n.1-2, p.19-21, jan/fev. 1996.

McGILVRAY, J. "Linkages, key sectors and development strategy". In: Leontief, W. (1977) Structure, system and economic policy. Cambridge: Cambridge University Press. Chap. 4, pp.49-56, 1977.

MILLER, R. E.; BLAIR, P. D. Input-output analysis: foundations and extensions. Englewood Cliffs, New Jersey: Prentice-Hall, Inc., 1985. $464 \mathrm{p}$.

MORETTO, A. C. Relações intersetoriais e inter-regionais na economia paranaense em 1995. Piracicaba, 2000. 161p. Tese (Doutorado) - Escola Superior de Agricultura "Luiz de Queiroz", Universidade de São Paulo.

PADIS, P. C. Formação de uma economia periférica: o caso do Paraná. São Paulo: Hucitec; Curitiba: Secretaria da Cultura e Esporte do Governo do Paraná, 1981. 235p.

RODRIGUES, R. L. Cooperativas agropecuárias e relações intersetoriais na economia paranaense: uma análise de insumo-produto. Piracicaba, 2000. 171p. Tese (Doutorado) - Escola Superior de Agricultura “Luiz de Queiroz", Universidade de São Paulo.

VOLACO, G.; BAGGIO, E. C.; SHIBATA, E. K.; LOURENÇO, G.M. Economia paranaense: desempenho recente e cenários de curto prazo. Análise Conjuntural, v.13, n.4, p. 1-9, abr. 1991.

WOSCH, L. F. As exportações paranaenses: expectativas superadas em 1995. Análise Conjuntural, v. 18, n. 1-2, p. 17-19, jan/fev. 1996. 


\begin{abstract}
The article had as objective to evaluate the evolution of the productive structure and identify the key sectors of Parana in the years of 1980, 1985, 1990 and 1995, highlighting the food processing sectors, using estimated input-output matrices. The results showed that the sectors of the transformation industry linked to the food processing sectors lost relative importance in the Parana economy, as much for the linkages with to the other sectors, as for the generation of production value and added value. This loss was more stressed in the more traditional food processing sectors, as Coffee Industry and Vegetal Products, instead of in most modern, as Meat Products, Dairy Products, Sugar Products and Vegetal Oil. Moreover, the production and the income had answered little to the impacts in the final demand in the food processing sectors throughout the analyzed period. Another trend that could be delineated was the change in the productive structure of the State, that became more diversified and complex, in direction of some sectors of the branch services and others emergent ones of the transformation industry, as metallurgy, mechanics and transport equipment.
\end{abstract}

Keywords: input-output, productive structure, key-sectors e food processing sectors. 